\title{
Ischemic Heart Disease. Hospitalization, Length of Stay and Expenses in Brazil from 1993 to 1997
}

\author{
Ruy Laurenti, Cassia Maria Buchalla, Carla Vanessa de Sousa Caratin
}

São Paulo, SP - Brazil

\begin{abstract}
Objective - To identify characteristics of the hospitalizations due to ischemic heart disease (IHD) made by the Single Health System - "Sistema Único de Saúde (SUS) in Brazil from 1993 to 1997.
\end{abstract}

Methods - The information used came from records of permissions for hospitalization due to IHD (diseases codified from 410 to 414 by the International Disease Classification $-9^{\text {th }}$ Revision) furnished by the data bank DATASUS. The material studied was classified according to age, sex and length of hospitalization of the patients, and expenses to the system for IHD.

Results - IHD represents $1.0 \%$ of total hospitalizations. Angina pectoris was the most frequent type, occurring in $53.3 \%$ of the cases, followed by acute myocardial infarct $(26.6 \%)$. This later was more frequent in men and angina in women. The majority of patients with IHD stayed hospitalized from 5 to 8 days. In the years of 1997 the expenses due to hospital treatment for IHD reach to $0.01 \%$ of Brazil's Gross Internal Product. In the studied period (1993-1997), IHD was responsible by 1.0\% of hospitalizations, however it was $3.3 \%$ of the expenses of SUS.

Conclusion - IHD is an important cause of hospitalization by the SUS; it has a rather high cost, indicating the need for preventive measures aimed at reducing exposure to risk factors and to decrease the incidence of this group of diseases in the nation.

Keywords: ischemic heart disease, hospitalization, espenses
Centro Brasileiro de Classificação de Doenças do Departamento de Epidemiologia da Faculdade de Saúde Pública - USP

Mailing address: Ruy Laurenti - Av. Dr. Arnaldo, 715 - 01245-904 - São Paulo, SP-Brazil
All over the world, cardiovascular diseases (CVD) are an important cause of death. By and large, this group of diseases represents a first cause, not only in developed but also in countries in the process of development. In Brazil, in the first half of the nineties, CVD were responsible for approximately $30 \%$ of all deaths ${ }^{1,2}$.

Among CVDs, ischemic heart disease and its different clinical manifestations, stands out in magnitude. The importance of CVD, was stressed by several studies that revealed an increase of mortality due to IHD in SãoPaulo municipality from the forty to eight decades ${ }^{1-6}$, folowed by a fall ${ }^{7}$. Besides their marked participation in overall mortality ${ }^{1,7-9}$.

Just as mortality studies encourage specific preventive activities, the analysis of the frequency of hospital morbidity by this group of diseases results in a greater source of information. Analysis of the causes of hospitalization permits the evaluation of their frequency, time of patients' stay in the hospital, expenses incurred and other factors. Considering that available medical resources permit ever earlier diagnosis and use of the latest generation of treatments leading to increased patient survival, records of hospital and outpatient morbidity have become the best and biggest source of information about these diseases, in particular, in their chronic forms.

Studies of morbidity statistics are difficult to perform, are performed less frequently and almost always refer only to limited population samples. Nevertheless, several investigators have approached this theme in studies on the prevalence of arterial hypertension in Rio Grande do Sul ${ }^{10}$, and on risk factors of chronic diseases, Rego et al ${ }^{11}$, Martins et $\mathrm{al},{ }^{12}$, and Chor, $1996^{13}$, among others.

The description of the pattern of morbidity of IHD in Brazil, as well as of its approximate magnitude in the country as a whole, can be made using the only available source, namely the hospitalization data supplied by the System of Hospitalization Information SIH/SUS. Even though this system deals only with hospitalizations paid for by the SUS, it represents $80 \%$ of the medical and hospital assistance of approximately 12 million hospitalizations per annum.

Data generated by records of admittances to the hospital are an easily assessed source of a large amount of in- 
formation allowing acquisition of data of fundamental importance for action in the health field.

Making use of such data, we aimed at the study of some characteristics of hospitalization due to ischemic heart disease, from 1993 to 1997, including types of manifestations, sex and age of the patients, as well as of duration and costs of their hospitalizations.

\section{Methods}

The study used records of the gross of secondary hospitalizations paid for by the SUS, represented by authorizations for admittance to the hospital obtained via CDROM from the Health Ministry, DATASUS, for the period between 1993 and 1997. Data were selected according to the Ninth Revision of the International Disease Classification (CID-9), which provides the following disease specifications or descriptions:

Ischemic heart disease (IHD) (410-414): acute myocardial infarct (410); other acute or subacute forms of IHD (411) including acute coronary insufficiency, intermediary syndrome, Dressler's syndrome and pre-infarct; old myocardial infarct (412); angina pectoris (413) - including cardiac angina, angina decubitus, angina of effort and anginous syndrome; other forms of IHD (414) - including coronary atherosclerosis, atherosclerotic heart disease, coronary sclerosis, myocardial ischemia and heart aneurysm.

This group of diseases constitutes an aggregate within the chapter of circulatory diseases that was used in this study for comparisons between averaged in-hospital periods.

Cases were selected according to information referring to these manifestations or descriptions and were analyzed according to the characteristics of the patient: age, sex, mean duration of stay (in days) and amounts paid for hospitalization (in reais).

Results are presented as sums of cases between 1993 and 1997, with the exception of amounts paid for hospitalization, which refer to 1997 only, because data from preceding years were not available on CD-ROM.

The amounts paid for hospitalization represent the cost per hospitalization to the system-and not real cost. Nevertheless, the term "cost" was used in this study as a synonym for the amount paid because it is recognized by usage. Expense, as well as time of permanence are limited by the rules of the SUS, and cannot, therefore, serve as parameters for international comparisons or even to affirm this to be the real expense or time of confinement for each case. They do allow, however, for comparisons to be made with other causes of hospitalization by the same system by the same rules.

\section{Results}

Between 1993 and 1997, 689,825 patients were admitted to the hospital due to IHD (410-414); they represent $10.1 \%$ of all hospitalizations due to circulatory diseases and $0.99 \%$ of the total authorizations for hospitalizations due to all causes. In relation to sex, the typical and specific pattern of this group of diseases is worth noting; $54.3 \%$ of the hospitalizations due to IHD were males and $45.7 \%$ of females. This pattern is inverted when hospitalizations due to causes other than IHD are analyzed; here, $65 \%$ of the patients were women and $35 \%$, men.

Their major cause for hospitalization being parturition or its complications, the high percentage of women hospitalized seems justifiable. However, even when hospitalizations due to parturition are excluded, $54.7 \%$ of the hospitalizations are still for females and $45.4 \%$ are for males.

Over the time span analyzed, a reduction (20.9\%) from $15,617,080$ to $12,351,464$ of total hospitalizations was noted. Hospitalizations for circulatory diseases decreased $27.1 \%$ (from 1,613,070 to 1,176,300), and for ischemic heart disease $29.8 \%$ (from 168,216 to 118,090). Reduction of hospitalizations were observed for all causes the lowest one for illdefined causes $(5.3 \%)$, followed by respirattory disesase (14.2\%) and congenital abnormalities (14.7\%). Reductions greater than those observed for IHD were observed only for infectious and parasitic diseases $34.6 \%$; neoplasms $32.3 \%$, genitourinary diseases $37.3 \%$ and osteomuscular diseases $33.5 \%$. Data regarding manifestations or type of ischemic heart diseases are shown on table I.

The group representing cases of angina pectoris (which includes also others of this description - 413) was responsible for $53.3 \%$ of the total, with a higher frequency of females $(60.8 \%)$ than males $(47.0 \%)$. Acute myocardial infarction (410) was responsable for $26.5 \%$ of the total hospitalizations and it was more frequent in men. Diagnosis of old myocardial infarcts (412) was least frequent, $0.4 \%$ of the IHD. Table II shows the distribution of IHD according to age and sex.

As expected, frequency of hospitalization due to IHD increased with age in both sexes (table II). It was also noted that with the exception of cases of angina pectoris, hospitalization of male patients was higher for all age groups.

Cases of acute myocardial infarct were 13.1 higher for men aged 65 years or more, in comparison with those aged 35 years or less. Among women aged 65 years or more, the number of hospitalizations was 22.6 times higher than for those aged 35 years or less. However, when the total of hospitalizations due to IHD is taken into consideration, this difference practically disappeared, changing to 32.5 and 31.8 times, respectively. This suggests that acute myocardial infarcts, still an acute manifestation of a chronic disease, affect younger men more frequently. In females it is the result of a longer process, which is prevalent in older groups. A more specific focus using coefficients might confirm this appraisal.

Regarding length of hospitalization in days, results are shown in table III: angina pectoris cases (413) showed the lowest confinement. Both acute and subacute (411) and long-standing myocardial infarct and other forms of IHD (412 and 414) required on average the longest periods of hospitalization.

It is to be noted that the average increase in days of hospitalization in the group of other acute and subacute 


\begin{tabular}{|c|c|c|c|c|c|c|}
\hline \multirow[b]{2}{*}{ Diagnosis } & \multicolumn{2}{|c|}{ Males } & \multicolumn{2}{|c|}{ Females } & \multicolumn{2}{|c|}{ Total } \\
\hline & $\mathrm{n}^{\circ}$ & $\%$ & $\mathrm{n}^{\circ}$ & $\%$ & $\mathrm{n}^{\circ}$ & $\%$ \\
\hline 410 - Acute myocardial infarct & 114649 & 30.8 & 67151 & 21.5 & 181800 & 26.6 \\
\hline 411 -Other acute and subacute forms & & & & & & \\
\hline of ischemic hear disease & 57494 & 15.5 & 37730 & 12.1 & 95224 & 13.9 \\
\hline 412 - Long-standing myocardial infarct & 1583 & 0.4 & 1040 & 0.3 & 2623 & 0.4 \\
\hline 413 - Angina pectoris & 174881 & 47.0 & 189991 & 60.8 & 364872 & 53.3 \\
\hline 414 - Other forms of ischemic heart disease & 23443 & 6.30 & 16828 & 5.4 & 40271 & 5.9 \\
\hline $410-414$ & 372050 & 100 & 312740 & 100 & $684790 *$ & 100 \\
\hline
\end{tabular}

* Cases of uninformed sex are excluded from the total

\begin{tabular}{|c|c|c|c|c|c|c|c|c|c|c|c|c|c|c|}
\hline \multirow{2}{*}{$\begin{array}{r}\text { Age/Sex } \\
\text { Ischemic heart disease }\end{array}$} & \multicolumn{2}{|c|}{$15-24 y$} & \multicolumn{2}{|c|}{$25-34 y$} & \multicolumn{2}{|c|}{$35-44 y$} & \multicolumn{2}{|c|}{$45-54 y$} & \multicolumn{2}{|c|}{$55-64 y$} & \multicolumn{2}{|c|}{65 or more y } & \multicolumn{2}{|c|}{ Total } \\
\hline & M & $\mathrm{F}$ & M & $\mathrm{F}$ & M & $\mathrm{F}$ & M & $\mathrm{F}$ & M & $\mathrm{F}$ & M & $\mathrm{F}$ & M & $\mathrm{F}$ \\
\hline $\begin{array}{l}410 \text { - Acute myocardial infarct } \\
411 \text { - Other acute and subacute } \\
\text { form of ischemic }\end{array}$ & 489 & 262 & 2706 & 1203 & 11921 & 5108 & 25173 & 10883 & 32428 & 16582 & 41932 & 33113 & 114649 & 67151 \\
\hline heart disease & 224 & 186 & 920 & 687 & 5330 & 3138 & 13262 & 7651 & 18895 & 11582 & 18863 & 14486 & 57494 & 37730 \\
\hline 412 - Old myocardial infarct & 15 & 4 & 52 & 27 & 168 & 103 & 357 & 199 & 396 & 268 & 595 & 439 & 1583 & 1040 \\
\hline 413 - Angina pectoris & 1040 & 1156 & 4998 & 5216 & 18671 & 20122 & 37947 & 40200 & 49617 & 49958 & 62608 & 73339 & 174881 & 189991 \\
\hline $\begin{array}{l}414-\text { Other forms of ischemic } \\
\text { heart disease }\end{array}$ & 296 & 284 & 710 & 814 & 2371 & 1743 & 5268 & 3252 & 7343 & 4687 & 7455 & 6048 & 23443 & 16828 \\
\hline $410-414$ & 2064 & 1892 & 9386 & 7947 & 38461 & 30214 & 82007 & 62185 & 108679 & 83077 & 131453 & 127425 & 372050 & 312740 \\
\hline
\end{tabular}

\begin{tabular}{|c|c|c|}
\hline \multicolumn{3}{|c|}{$\begin{array}{l}\text { Table III - Average confinement (in days) during hospitalizations } \\
\text { paid for by the SUS according to type of manifestation of ischemic } \\
\text { cardiac disease }\end{array}$} \\
\hline Ischemic cardiac disease & 1993 & 1997 \\
\hline 410 - Acute myocardial infarct & 7.6 & 8.0 \\
\hline 413 - Angina pectoris & 5.6 & 5.9 \\
\hline \multicolumn{3}{|l|}{$\begin{array}{l}412 \text { e } 414 \text { - Old myocardial infarct } \\
\text { and other forms of ischemic }\end{array}$} \\
\hline heart disease & 8.0 & 8.8 \\
\hline $410-414$ & 6.5 & 7.2 \\
\hline Diseases of the circulatory system & 7.2 & 7.2 \\
\hline All causes & 6.7 & 6.4 \\
\hline
\end{tabular}

forms of IHD (411) was 27.6\%, but when comparing data for the whole of IHDs (410-414), an increase of $10.8 \%$ between 1993 and 1997 was observed.

Regarding the total of circulatory diseases, no changes were noted, but the average days of hospitalization for all causes had a small decrease.

The period of hospitalization for all types of IHD ranged between 5 and 8 days. Of the total number of hospitalizations due to IHD in 1997, $2.0 \%$ of patients remained in the hospital for 29 days or longer; the same percentage remained 22 to 28 days. However, as already mentioned, these data are limited by the rules of the SUS. Regarding cost, that is, the amounts paid by the SUS for hospitalizations in 1997, table IV shows its total value (in Reais) for IHD and its different manifestations. For comparison, amo- unts referring to the total of hospitalizations due to all causes and the total of hospitalizations for diseases of the circulatory system are also shown.

Expenses for hospitalization for IHD in 1997 reached values above 100 million reais, corresponding to $3.3 \%$ of the total amount spent on hospitalization and approximately equivalent to $20 \%$ of that corresponding to the whole of hospitalizations due to circulatory system diseases. The average cost per hospitalization due to IHD was twice as high as the average value spent on diseases of the respiratory system and slightly more than three times higher than the average cost of the total number of hospitalizations for all causes.

\section{Discussion}

The number of hospitalizations due to IHD between 1993 and 1997 was rather high, equivalent to approximately $1 \%$ of hospitalizations for all causes. It should however be taken into account that this number may have been underestimated because doctors do not always report the basic disease, reporting instead only its complication, for example specifying cardiac insufficiency as congestive or not.

Actually, during the period studied, 2,345,981 patients were hospitalized with this diagnosis; its distribution by age group is similar to that of IHD. However, it can be verified that for cases of cardiac insufficiency no great difference exists between sexes, some age groups exhibiting a larger 
number of hospitalizations of persons of the feminine sex. Despite this, it is not difficult to imagine an appreciable segment of this total of patients to have Ischemic heart disease as the primary or basic factor of illness.

For this reason, it can be stated almost with certainty that the number of hospitalizations due to IHD, as shown in the results, is a minimal one. It must also be recalled that besides cardiac insufficiency, part of the cases diagnosed as cardiac arrhythmia, heart disease and cardiopathy among others could also be added to this group.

Thus, we have to stress that the present analysis included only patients admitted to SUS or SUS-paid hospitals with exclusion of emergency room and day patients.

As already described, a decrease in the total number of hospitalizations was observed. This was due to a resolution of the Health Ministry, which extensively altered criteria for admittance for all causes; however, the reduction due to IHD (29.8\%) was higher than the reduction for all causes $(20.9 \%)$. It may be speculated that besides the administrative measures, which reduced hospitalizations, a decrease in cases of IHD had occurred. This fact has been described ${ }^{14}$ in regard to mortality in the State of São Paulo, which showed a decrease of $28.3 \%$.

These data could lead to the hypothesis of a decreased incidence, influencing IHD mortality figures as described. However, this cannot be confirmed, because the present type of study would not be appropriate for this type of evaluation.

Regarding the type of the manifestations of IHD, we observed that angina pectoris - stood out with $53.3 \%$ of the cases, being the most frequent cause for hospitalization of women, followed by myocardial infarcts, more frequent in men. Admittances due to old myocardial infarcts were minimal at $0.4 \%$.

Even though angina pectoris was responsible for the largest number of hospitalizations, it required the smallest average lengths of hospitalization, 5.6 and 5.9 days in 1993 and 1997, respectively. The highest average numbers of

\begin{tabular}{|c|c|c|}
\hline \multicolumn{3}{|c|}{$\begin{array}{l}\text { Table IV - Total and average expenses according to type of confine- } \\
\text { ment. Ischemic heart disease, circulatory diseases and all causes }\end{array}$} \\
\hline Internment & $\begin{array}{l}\text { Total value } \\
\quad(\mathrm{R} \$)\end{array}$ & $\begin{array}{c}\text { Average } \\
\text { per confinement } \\
(\mathrm{R} \$)\end{array}$ \\
\hline $\begin{array}{l}410 \text { - Acute myocardial infarct } \\
411 \text { - Other acute and subacute } \\
\text { forms of ischemic }\end{array}$ & $21.361 .083,85$ & 629,89 \\
\hline $\begin{array}{l}\text { heart disease } \\
412 \text { - old }\end{array}$ & $38.397 .717,84$ & 2395,36 \\
\hline myocardial infarct & $263.932,15$ & 773,99 \\
\hline 413 - Angina pectoris & $29.411 .985,51$ & 480,72 \\
\hline $\begin{array}{l}414 \text { - Other forms of } \\
\text { ischemic heart disease }\end{array}$ & $15.065 .733,04$ & $2.274,07$ \\
\hline $410-414$ & $104.500 .452,39$ & 884,92 \\
\hline Diseases of the circulatory system & $522.779 .048,84$ & 444,42 \\
\hline $\begin{array}{l}\text { Diseases of the circulatory system } \\
\text { except IHD }\end{array}$ & $418.278 .596,45$ & 395,26 \\
\hline Total hospitalizations & $3.205 .852 .023,00$ & 259,55 \\
\hline Total hospitalizations minus IHD & $3.101 .351 .570,61$ & 253,51 \\
\hline
\end{tabular}

days of hospitalization was that corresponding to other forms of acute and subacute ischemic heart disease, followed by old infarcts and other forms of IHD. The average length of the total hospitalizations due to IHD in 1997 was the same as that for hospitalizations due to circulatory diseases and greater than the average length of confinement for all other causes.

Results show that average days of hospitalization for IHD in all of its manifestations, especially those of the acute and subacute forms, increased $27.6 \%$ compared with those in 1993 . However this is mainly the result of a single observation and cannot be used to form - hypotheses. Mc Govern et $\mathrm{al}^{15}$, studying aspects and tendencies of mortality, morbidity, medical services and risk factors of acute myocardial disease in the metropolitan area of Minneapolis and St. Paul, Minnesota, USA, verified a decrease on in the average time of confinement due to acute heart infarcts from 1985 to 1990 . It decreased from 8.5 to 6.2 days for males and from 8.9 to 6.9 days for females. This study allowed the authors to conclude that substantial changes had occurred in the proportion of patients who underwent special surgical procedures or used certain types of medication. Thus, the frequency of the use of thrombolytic therapy was more than twice as high (up from 13 to $30 \%$ ), coronary angioplasty went from 5 to $21 \%$, the use of aspirin from 27 to $81 \%$ and of heparin from 53 to $75 \%$. In contrast, a moderate but statistically significant decline in the use of warfarin (down from 20 to $14 \%$ ) and of beta-blockers (down from 56 to $50 \%$ ) was observed. The authors discuss these findings, relating them mainly to the rate of hospitalization, decreased incidence and risk factors.

In our case as already mentioned, no discussion concerning alterations in average hospitalization times is possible. This is an interesting observation and deserves special study, for which it is important to remember that administrative factors controlling length of hospitalization may have occurred.

The results also show that hospitalization due to acute myocardial infarct in patients 65 years or older compared to with those less than 35 years old is considerably greater in females compared to with males (22.6 times against 13.1 times, respectively). This result agrees with that observed clinically and epidemiologically in other cases: frequency and mortality due to acute myocardial infarct in the aged are higher in women. It is worth pointing out, however, that this result was not observed for the group of hospitalizations due to ischemic heart diseases.

The results of the present study show that hospitalization expenses due to IHD in 1997 reached a value above 100 million reais. This represents approximately $0.012 \%$ of the gross national product of that year. The global expense with this disease can be evaluated by taking into account that this is the lowest amount spent on hospitalizations paid for by the SUS, and that the real cost of each condition studied was not taken into account.

We wish to point out that for the period between 1993 and 1997 hospitalizations due to IHD were $0.99 \%$ of the total and that the expenses $(3.26 \%)$ paid for by the SUS with these hospitalizations cost three times as much as expenses for all other hospitalizations. 
In truth, expenses due to IHD are rather high in Brazil, running above those of other diseases and leading the SUS to adopt measures aimed at the reduction of hospitalizations as well as length of time of confinement. Such reductions could be achieved on in the medium- or long- range by supplying resources to be applied to educational activities aimed at the reduction of exposure to risk factors. Such a measure would reduce the incidence of ischemic heart disease, decreasing not only hospitalization but also mortality rates ${ }^{14}$.

\section{References}

1. Chor D, da Fonseca MJ, de Andrade CR, Waissman W, Lotufo PA. Doenças cardiovasculares, panorama da mortalidade no Brasil. In: Minayo MC (org). Os muito Brasis. Saúde e População na Década de 80. São Paulo - Rio de Janeiro: Hucitec/Abrasco, 1995;pp. 57-86.

2. Chor D, da Fonseca MJ, de Andrade CR. Doenças cardiovasculares: comentários sobre a mortalidade precoce no Brasil. Arq Bras Cardiol 1995; 64: 15-9.

3. Laurenti R, Fonseca LAM. A mortalidade por doenças cardiovasculares no município de São Paulo em um período de 30 anos (1940-1969). Arq Bras Cardiol 1976; 29: 85-8.

4. Laurenti R, Fonseca LAM. A evolução da mortalidade por doença isquêmica do coração no município de São Paulo de 1940 a 1973. Arq Bras Cardiol 1977; 30: 351-5.

5. Lolio CA, Laurenti R. Tendência da mortalidade por doenças cerebrovasculares em adultos maiores de 20 anos de idade no município de São Paulo. Rev Saúde Pública, 1986; 20: 433-6.

6. Lolio CA, Laurenti R. Evolução da mortalidade por doença isquêmica do coração no município de São Paulo, 1970 a 1981. Arq Bras Cardiol 1986; 46: 153-6.

7. Lotufo PA, Lolio CA. Tendência da mortalidade por doença cerebrovascular no estado de São Paulo, 1970-1989. Arq Neuro-Psiquiatria 1993; 51: 441-6.

8. Lessa I. Anos produtivos de vida perdidos no Brasil por mortalidade cardiovascular. Bol of Sanit Panam 1991; 110: 118-25.
9. Lessa I, Silva MRBB. Doenças cerebrovasculares como causa múltipla de morte em Salvador. Arq Neuro-Psiquiatria 1993; 51: 319-24.

10. Klein CH. Hipertensão arterial nos estratos geo-econômicos do Rio Grande do Sul.. Tese de mestrado. Escola Nacional de Saúde Pública/FIOCRUZ. Rio de Janeiro, 1984

11. Rego RA, BerardoFA, Rodrigues SS, et al. Fatores de risco para doenças crônicas não transmissíveis: inquérito domiciliar no município de São Paulo, S.P. (Brasil). Metodologia e resultados preliminares. Rev Saúde Pública 1990; 24 : 277-85.

12. Martins IS, Marucci M de F, Cervato AM, Okani ET, Mazzilli RN, Casajus MI Doenças cardiovasculares ateroscleróticas, dislipidemias, hipertensão, obesidade e diabetes melito em população da área metropolitana da região sudeste do Brasil. II - Dislipidemias. Rev Saúde Pública, 1996; 30: 75-84.

13. Chor D. Perfil de risco cardiovascular de funcionários de banco estatal. Tese de doutorado. Faculdade de Saúde Pública, USP. São Paulo, 1996.

14. Lotufo PA. A mortalidade precoce por doenças crônicas nas capitais de regiões metropolitanas do Brasil. Tese de Doutorado. Faculdade de Saúde Pública, USP. São Paulo, 1996.

15. Mc Govern PG, Pan Kow JS, ShaharE, et al. Recent trends in acute coronary heart disease. Mortality, morbidity, medical care and risk factors. N Engl J Med 1996; 334: 884-90. 